\title{
A NEW SPECIES OF THE GENUS Trigonura Sichel, 1865 (Hymenoptera: Chalcididae) FROM VIETNAM
}

\author{
Khuat Dang Long*, Nguyen Duc Hiep, Dang Thi Hoa, Tran Thi Ngat \\ Institute of Ecology and Biological Resources, VAST, Vietnam
}

Received 26 July 2019, accepted 2 October 2019

\begin{abstract}
Based on the specimens of chalcid parasitoid wasps collected by malaise traps set in fruit orchards in the adjacent area of Ha Noi city from 2018-2019, one new species of the genus Trigonura, $T$. vietnamica Long, sp. n., was described and illustrated. Two species of this genus from Vietnam are keyed, the comparative characters of the new species were also given to compare with two similar species from the Oriental Region, $T$. indica Narendran and $T$. luzonensis Narendran.
\end{abstract}

Keywords: Chalcididae, Trigonura, new species, parasitoid wasps, Oriental, Vietnam.

Citation: Khuat Dang Long, Nguyen Duc Hiep, Dang Thi Hoa, Tran Thi Ngat, 2019. A new species of the genus Trigonura Sichel, 1865 (Hymenoptera: Chalcididae) from Vietnam. Academia Journal of Biology, 41(4): 1-6. https://doi.org/10.15625/2615-9023/v41n4.14030.

*Corresponding author email: khuatdanglong@gmail.com

(C2019 Vietnam Academy of Science and Technology (VAST) 


\section{INTRODUCTION}

The family Chalcididae Latreille, 1817 (Hymenoptera: Chalcidoidea), a moderatesized family within the Chalcidoidea, is apparently polyphyletic, though the different subfamilies. The family composed mostly of parasitoids and few hyperparasitoids. As presently defined, there are about 90 valid genera and approximately 1500 valid species so far described from the world (Noyes, 2011; Narendran \& van Achterberg, 2016). The genus Trigonura Sichel, 1865 is one of the moderately diverse genus among the family Chalcididae, and up to date, the genus comprises twenty nine valid species, of those eleven species were reported from the Oriental region. The Chalcididae of Vietnam was revised by Narendran \& van Achterberg (2016) with 16 genera and 68 species reported, and in this work there was one species, Trigonura luzonensis Narendran, 1987, was recorded from Vietnam. In this paper we aim to report the discovery of another one new species of the genus Trigonura Sichel, 1865 from Vietnam.

\section{MATERIALS AND METHODS}

This study is based on the chalcid wasp specimens captured by malaise traps set in fruit orchards in the surrounding areas of $\mathrm{Ha}$ Noi city from 2018 through 2019. All the specimens, including types are deposited in the Parasitic Hymenoptera Collection at the Institute of Ecology and Biological Resources (IEBR), Vietnam Academy of Science and Technology (VAST), Ha Noi, Vietnam.

Terminology used in this paper follows Narendran \& van Achterberg (2016). For identification of the genera of the subfamily Chalcididae, see Narendran \& van Achterberg (2016). For virtually all species we used an Olympus ${ }^{\circledR}$ SZ61 binocular microscope; key to species and description of species are based on female; measurements were carried out using an Olympus $^{\circledR}$ SZ40 binocular microscope; The colour photographs were made with Sony ${ }^{\circledR} 5000$ digital camera attached to a Nikon ${ }^{\circledR}$ SMZ $800 \mathrm{~N}$ binocular microscope connected to a PC at IEBR. The scale-lines of the plates indicate in $\mathrm{mm}$. Abbreviations used in this paper are as follows: $\mathrm{POL}=$ postocellar line; $\mathrm{OOL}=$ ocular-ocellar line; $\mathrm{OD}=$ diameter of posterior ocellus; MT: Malaise trap; "Chalcid.+number': code number indexing for specimens of the Chalcididae in the collection at IEBR; $\mathrm{N}=$ North, STCT = Department of Insect Ecology. All types of the new species are deposited in IEBR (Ha Noi, Vietnam).

\section{RESULTS}

\section{SYSTEMATICS}

\section{Trigonura Sichel, 1865}

Trigonura Sichel, 1865: 358, 376-377 (as subgenus of Phasganophora Sichel, 1865).

Type species: Phasganophora crassicauda Sichel, by monotypy.

Bactrochalcis Kieffer, 1912: 463. Type species: Bactrochalcis reticulata Kieffer, by monotypy. Synonymised with Trigonura Sichel by Steffan (1951b).

Centrochalcis Cameron, 1913: 92. Type species: Centrochalcis ruficaudis Cameron, by monotypy. Synonymised with Trigonura Sichel by Waterston (1922).

Centrochalcidea Gahan \& Fagan, 1923: 28. Replacement name for Centrochalcis Cameron, 1913, not 1905.

Chalcidellia Girault, 1924a: 1-3. Type species: Chalcis euthyrrhini Dodd, by original designation. Synonymised with Trigonura Sichel by Bouček (1988b).

Urochalcis Nikol'skaya, 1952: 91. Type species: Urochalcis ninae Nikol'skaya, by original designation. Synonymised with Trigonura Sichel by Nikol'skaya (1960).

\section{Checklist and distribution of Trigonura species of the Oriental region}

Trigonura bakeri Masi, 1926/Philippines.

Trigonura gladiator (Walker, 1862)/ Malaysia.

Trigonura indica Narendran, 1987/India.

Trigonura javensis Narendran, 1987/ Indonesia. 
A new species of the genus Trigonura

Trigonura luzonensis Narendran, 1987/ India, Philippines, Vietnam.

Trigonura nishidai Narendran, 1989/ China, Laos.

Trigonura samarensis Narendran, 1987/ India, Philippines.

Trigonura shonima Narendran,

1989/ Malaysia.

Trigonura steffani Narendran, 1987/India.
Trigonura tenuicaudis Waterston, 1922/ India.

Trigonura townesi Narendran, 1989/ Malaysia.

Trigonura vietnamica Long, sp. n./ Vietnam.

\section{Key to Vietnamese species of Trigonura Sichel}

1. In lateral view, scutellum highly convex anteriorly higher upper level of mesoscutum (Fig. 200 in Narendran \& van Achterberg, 2016); PMV longer than STV; hind femur and tibia completely black.........................................T. luzonensis Narendran, 1987

- In lateral view, scutellum convex medially, almost at the upper level of mesoscutum (Figs 1, 4); PMV $0.7 \times$ STV (Fig.); hind femur brown, except baso-dorsally and apico-ventrally redish-yellow; tibia mostly brownish-yellow, infuscate basally.... T. vietnamica Long, sp. n

\section{Description of species}

Trigonura vietnamica Long, sp. n. (Figs 1-9)

Material. Holotype, + , "Chalcid.0068" (IEBR), N Vietnam: Ha Noi, Tu Liem, Minh Khai, fruit orchard, MT, $20^{\circ} 23^{\prime} \mathrm{N} 105^{\circ} 34^{\prime} \mathrm{E}, 8$ m, 20-30.iv.2019, STCT. Paratypes, 2 q, "Chalcid.0069", "Chalcid.0070" (IEBR), ibid; paratype, 1 ㅇ, "Chalcid.0071" (IEBR), N Vietnam: Ha Noi, Chuong My, Thuy Xuan Tien, fruit orchard, MT, $20^{\circ} 52^{\prime} 59.7^{\prime \prime} \mathrm{N}$ 105 34'35.5'E, 11 m, 20-30.iv.2019, STCT.

Diagnosis. Differences between Trigonura vietnamica Long, sp. $\mathrm{n}$. and T. luzonensis Narendran, 1987, from Philippines and Vietnam (Narendran \& van Achterberg, 2016) are given in the key, the new species can be distinguished from $T$. luzonensis by the following characters: a) POL $2.2 \times$ OOL (2.5$3.1 \times$ in $T$. luzonensis); b) PMV distinctly shorter than STV (slightly longer than STV in T. luzonensis); c) in lateral view, scutellum slightly convex, and almost at the same level of mesoscutum (highly convex above level of mesoscutum in T. luzonensis); d) T1 $1.1 \times$ its width (T1 shorter than its width in $T$. luzonensis); and e) Hind femur dark brown laterally, yellowish-red baso-laterally and apico-ventrally (blackish without any yellow spot in T. luzonensis).
Based on the diagnosis given by Narendran \& van Achterberg (2016), the new species is close to Trigonura indica Narendran, 1987, from India, but differs from the latter by the following characters: a) Hind femur densely and minutely punctate (in $T$. indica the punctures are less close on the hind femur); and b) Hind femur dark brown laterally, reddish-yellow baso-laterally and apico-ventrally (in $T$. indica hind femur yellowish-red with a distinct characteristic yellow spot at the apex).

Description. ㅇ, length of body $5.7 \mathrm{~mm}$, fore wing $3.2 \mathrm{~mm}$, antenna $2.5 \mathrm{~mm}$ (Fig. 1).

Head. Middle antennal segment $2.0 \times$ as long as wide (10:5); apical antennal segment $1.7 \times$ as long as subapical segment (12:7); in dorsal view, POL $2.2 \times$ OOL; POL : OD : $\mathrm{OOL}=13: 4: 6$ (Fig. 2); face, frons, vertex and temple foveolate-rugose; area between scrobes finely transversely strigate-rugose.

Mesosoma. In lateral view, scutellum slightly convex, almost at the same level of mesoscutum (Figs 1, 4); pronotum transversely rugose dorsally, foveolate-rugose laterally (Fig. 4); mesoscutum foveolatepuncticulate (Fig. 3), except anterior narrow transverse area of mesoscutum finely costate; scutellum foveolate-puncticulate; metanotum and scutellum apically crenulate (Fig. 6); 
propodeum areolate (Fig. 6); metapleuron setose, foveolate-rugose (Fig. 4).

Wings. Length of fore wing $2.1 \times$ as long as its maximum width (82:39); fore wing veins MV : STV : PMV = 16:6:4 (Fig. 9); length of hind wing $4.3 \times$ as long as its maximum width (56:13); hind wing with three hamuli.
Legs. Hind coxa densely setose basoventrally, almost smooth apically; hind femur with close minute setigerous pits, outer ventral margin with a row of 10 teeth, basal tooth distinctly larger than others, and size of teeth decreasing from base to apex (Fig. 7).

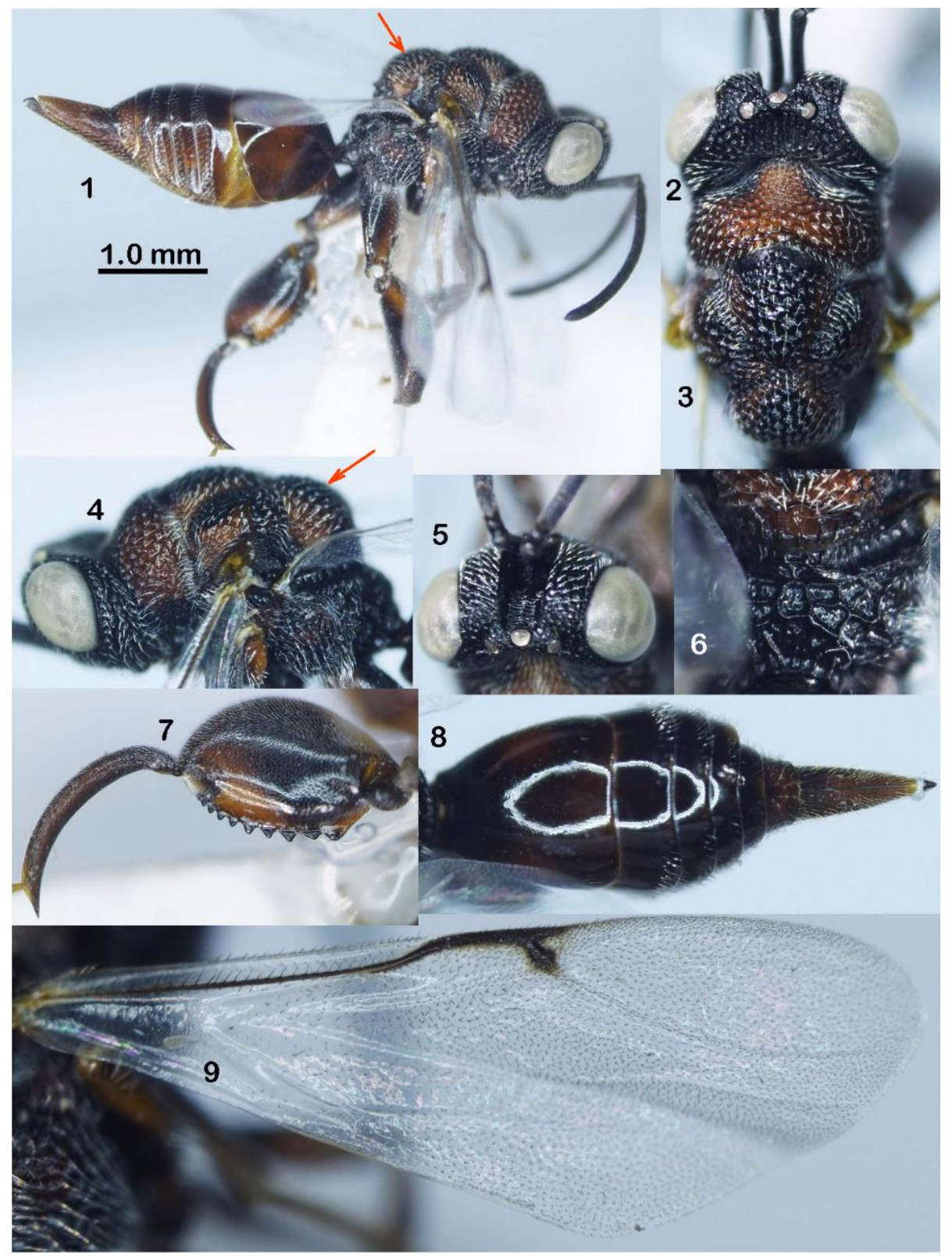

Figures 1-9. Trigonura vietnamica Long, sp. n. Holotype, female (lateral view) 1. Habitus, 2. Head dorsal view 3. Mesoscutum 4. Mesopleuron 5. Frons and scrobes 6. Metanotum and propodeum 7. Hind femur and tibia (lateral view) 8. Metasoma (dorsal view) 9. Fore wing 
Metasoma. First metasomal tergite (T1) $1.1 \times$ as long as wide (47:44) (Fig. 8); dorsally, epipygium long, with dorsal median carina (Fig. 8), $0.7 \times$ as long as T1 $(18: 26)$, and $0.3 \times$ as long as length of T1T6 (18: 57).

Colour. Head black; scapus black, except yellow at extreme base; antennae black; eye and ocellus eye and ocellus reflecting whitish-grey; mandible yellow, except its black tips; pronotum reddish-yellow, black ventrally; tegula yellow; lobes of mesoscutum blackish brown dorsally, reddish-yellow laterally; scutellum blackish brown dorsally, reddish-yellow laterally and apically; metanotum and propodeum black; fore and middle coxa dark brown to black; fore and middle femur and tibia yellow, but yellowish-brown dorsally; fore and middle tarsus yellow; hind coxa brown, but reddishyellow apico-ventrally; hind femur dark brown laterally, reddish-yellow basolaterally and apico-ventrally; fore wing veins pale brown; wing membrance hyaline.

\section{Male. Unknown.}

Etymology. The new species is named after the country, where the holotype was discovered (Vietnam).

Host. Unknown.

Distribution. N Vietnam: Ha Noi.

\section{DISCUSSION}

Recently, in the paper published by Narendran \& van Achterberg (2016), of the total 68 species belonging to 16 genera reported, 37 species and 11 genera were new for Vietnam. Probably this is the first taxonomical work dealing with chalcid wasps from Vietnam. Additionally, in the published paper by Narendran \& van Achterberg (2016), the chalcid specimens were mostly collected using malaise traps from Southern and North Central Vietnam. The previously recorded species of Chalcididae from Vietnam can also be found in the chalcidoid database: www.nhm.ac.uk/research-curation/research/ projects/chalcidoids/database/. Our small project aims to reveal chalcid wasps as parasitoids of coleopteran, dipteran and lepidopteran insect pests damaging agricultural and fruit crops in Northern and Southern Vietnam, many specimens of Chalcididae were collected from different habitats and are awaiting to be treated. In this paper, the discovery is only partly described, and unfortunately the host of this new chalcid wasp is unknown yet.

Acknowledegements: This research was supported by the Institute of Ecology and Biological Resources under the Basic Grants No. IEBR.DT.12-18 and IEBR.DT.1-19. Our thanks are due to Dr Cao Van Chi, director and and his staff of the Center for Citrus Research and Development, Chuong My District, Ha Noi City; two owners of citrus orchards, $\mathrm{Mr}$ Nguyen Trong Lan, Minh Khai ward, Bac Tu Liem District, Ha Noi City and Mr Lai Van Tựa from Thanh Lap Commune, Luong Son District, Hoa Binh Province for their generous help in the fieldwork. The authors would also like to express the deep gratitude to $\mathrm{Dr} \mathrm{Ha}$ Danh Duc from Dong Thap University, Cao Lanh City, Dong Thap Province for providing some unaccessible literatures.

\section{REFERENCES}

Bouček Z., 1972. On some European Chalcididae (Hymenoptera) with the description of a new Euchalcis Dufour. Entomologist's Gazette, 23(4): 237-242.

Bouček Z., 1982. Oriental chalcid wasps of the genus Epitranus. Journal of Natural History, 16: 577-622. https://doi.org/ 10.1080/00222938200770451.

Bouček Z., 1988a. An overview of the higher classification of the Chalcidoidea (Parasitic Hymenoptera). In: Gupta VK (Ed.) Advances in Parasitic Hymenoptera Research: Proceedings of the Second Conference on Taxonomy and Biology of Parasitic Hymenoptera, Gainesville, November, 1987, Leiden, 11-23.

Bouček Z., 1988b. Australasian Chalcidoidea (Hymenoptera) - A biosystematic revision of genera of fourteen families, with a 
reclassification of species. $\mathrm{CAB}$ International, Wallingford, $832 \mathrm{pp}$.

Bouček Z, 1992. The New World genera of Chalcididae. Memoirs of the American Entomological Institute, 53: 49-117, 443-46.

Burks B. D., 1959. The North American species of Trigonura (Hymenoptera; Chalcididae). Annals of the Entomological Society of America 52(1): 75-81. https://doi.org/10.1093/aesa/52.1.75

Darling D. C., 2009. A new species of Smicromorpha (Hymenoptera, Chalcididae) from Vietnam, with notes on the host association of the genus. ZooKeys, 20: 155-163. https://doi.org/10.3897/zookeys.20.195

Gahan A. B., Fagan M. M. 1923. The type species of the genera of Chalcidoidea or Chalcid-flies. Bulletin of the United States National Museum Washington, 124: 1173. https://doi.org/10.5479/si.03629236. 124.i

Girault A. A., 1913. On several new genera and species of Australian Hymenoptera Chalcidoidea. The Canadian Entomologist, 45: 101-106, 138-145. https://doi.org/10.4039/Ent45101-4

Habu A., 1960. A revision of the Chalcididae (Hymenoptera) of Japan with description of sixteen new species. Bulletin of National Institute of Agricultural Sciences, Tokyo (C), 11: 131-363.

Husain T., Agarwal M. M., 1981. Systematic studies on Indian Dirhininae (Hymenoptera: Chalcididae). Oriental Insects, 15(2): 179-193. https://doi.org/ 10.1080/00305316.1981.10434854.

Husain T., Agarwal M. M., 1982. Indian species of Brachymeria Westwood (Hymenoptera: Chalcididae). Oriental Insects 16: 491-509. https://doi.org/ 10.1080/00305316.1982.10433641.
Joseph K. J., Narendran T. C., Joy P. J., 1970. Four new species of Brachymeria Westwood (Hym., Chalcididae) from the Calicut region. Oriental Insects, 4: 281292. https://doi.org/10.1080/00305316. 1970.10433964.

Joseph K. J., Narendran T. C., Joy P. J., 1971. Two new species and three new subspecies of Brachymeria Westwood (Hym., Chalcididae) from the Mysore region. Oriental Insects, 5: 229-231. https://doi.org/10.1080/00305316.1971.10 434011

Joseph K. J., Narendran T. C., Joy P. J., 1972. Some new species of Oriental Brachymeria Westwood (Hymenoptera: Chalcididae) in the collections of the Bishop Museum, Honolulu. Oriental Insects, 6(3): 348-350. https://doi.org/ 10.1080/00305316.1972.10434084.

Mani M. S., Dubey O. P. 1972. On some Dirhinini (Hymenoptera: Chalcidoidea) from India. Oriental Insects, 6(3): 401408. https://doi.org/10.1080/00305316. 1972.10434089.

Narendran T. C., 1984. Key to Indian genera of the family Chalcididae (Hym.: Chalcidoidea). Entomophaga, 29(4): 431438. https://doi.org/10.1007/BF02372165

Narendran T. C., 1987. Oriental chalcid wasps of the genus Trigonura Sichel (Hymenoptera: Chalcididae). Entomon, 12(3): 288-289.

Narendran T.C., van Achterberg C., 2016. Revision of the family Chalcididae (Hymenoptera, Chalcidoidea) from Vietnam, with the description of 13 new species. ZooKeys, 576: 1-202. https://doi.org/10.3897/zookeys.576.8177.

Noyes J. S., 2011. Universal Chalcidoidea Database. https://www.nhm.ac.uk/ chalcidoids (accessed 19 July 2019). 